\title{
INFLUENCE OF AN UNEVEN SURFACE ON THE VIBRATION OCCURRENCE AFFECTING THE TRACTOR OPERATOR
}

\author{
Željko BARAČ, Ivan PLAŠČAK, Tomislav JURIĆ, Pavo BALIČEVIĆ, Vinko DUVNJAK, Mladen JURIŠIĆ, Goran HEFFER, \\ Monika MARKOVIĆ
}

\begin{abstract}
The paper presents a study of the influence of an uneven surface and number of tractor hours on vibration that is transmitted to the operator's hand-arm system during operation. The study was conducted on the asphalt, gravel and grass traversal during 2015 and 2016 . The results indicate that the movement of a tractor on different agrotechnical surfaces generates vibrations of varying intensity that affect the hand-arm system of the operator. The highest vibration values were recorded on the asphalt, while the least vibrations were measured on the grass. The measured maximum vibration values are lower than the permissible $5 \mathrm{~m} \cdot \mathrm{s}^{-2}$ in the direction of all three axes, making it possible to assume that they are not harmful to the health of the operator.
\end{abstract}

Keywords: agrotechnical surfaces; hand-arm system; vibration

\section{INTRODUCTION}

There are numerous negative effects of vibration on the operator. However, since vibration is closely intertwined with other occupational hazards, a clear causal link between the impact of vibration and health damage cannot be established. A wealth of research shows that constant shortterm exposure to high vibration can cause stomach and chest pain, lack of air, nausea and dizziness, whereas constant long-term exposure can result in psychomotor, physiological, and psychological disorders [1]. The structure of an agricultural tractor consists of a fixed connection between the axes and the tractor, which is especially unfavorable regarding the transmission of mechanical vibration to the operator's workplace. Mechanical vibration is transmitted through the operator's seat, the floor of tractor cabs, steering wheels, control and driving levers. The negative impact of mechanical vibration decreases the operator's concentration affecting his/her central nervous system and potentially causing occupational diseases of the spine and stomach $[1$, 2]. Vibration is an oscillatory body movement which can be straight or angular depending on the motion path. The increase in speed of agrotechnical practices has created new problems relating to the dynamic behavior of machinery and exposure of the operator's body to vibration. An increased speed of agrotechnical practices intensifies mechanical vibration, which consequently affects the operator [3].

Electrical and pneumatic hand-held tools can cause hand-arm vibration [4]. Depending on the intensity, frequency, and exposure period, the changes can be temporary (i.e. reversible) or permanent. Working in a cold environment increases injury risk. When exposed to vibration, it is necessary to avoid hand hypothermia (e.g. keep the hands warm using gloves or a source of heat). Furthermore, it is necessary to measure vibration in an objective way to determine the real danger to human health, as well as to develop mechanisms and equipment to protect the operator from the negative impact of vibration [5].
Authors [6] point out that cardiovascular disorders result from vibration exposure in which case operators often complain about occasional pain in hands or white fingers, which is a sign of hypothermia. Neurological disorders occur when hands and arms are exposed to vibration causing tingling and numbness of the hand or the whole arm. A muscle and the peripheral nervous system disorder affecting the hand or arm is a consequence of vibration exposure that produces irreversible changes in hand bones and wrist joints. Workers exposed to long-term vibration generally complain of muscle weakness and tingling in hands and arms. Additionally, vibration decreases the firmness of grip strength, which is considered a direct consequence of mechanical damage to peripheral nerves. Cardinale and Wakeling [7] argue that constant exposure to high vibration frequencies can significantly impair one's health. The operator's hand-arm system is the most susceptible to vibration within the frequency range of $6-16 \mathrm{~Hz}[8,9,10]$.

Fahy and Thompson [11] point out that the transfer of vibration to the operator's body occurs when the body is leaning against a vibrating surface (e.g. when in a seated position on a vibrating chair; in a standing position on a vibrating floor; in a lying position on a vibrating surface). Bogadi-Šre [12] claims that the operator exposed to general vibrations can develop osteoarticular diseases. The changes in the lumbar vertebrae in $90 \%$ of the general population aged between 55 and 60 can be confirmed by x-ray, whereas the same can be confirmed among $100 \%$ of the vibrationexposed population aged between 45 and 50. Zeng [13] claims that constant vibration exposure accompanied by the aging of the agricultural population presents a significant risk to their health. Therefore, a modification of vehicle design should facilitate a decrease in vibration created by agrotechnical practices. Pobedin et al. [14] point out that vibration reduction can be achieved by adding a vibration muffler into the tractor cab. Authors [15] claim that modern tractors are often equipped with parts that reduce the 
vibration transferred to the driver (e.g. low-pressure tyres, air sprung seat and cab, and front axle suspension).

Barač et al. [16] measured the vibration that affects the operator's hand-arm system when working with a sprayer and mulcher. The lowest vibration values were measured on a sprayer in the direction of the $x, y$ and $z$ axes. Barač et al. [17] researched the impact of various agrotechnical surfaces (asphalt, gravel and grass surface) on the level of vibration that affect the hand-arm system. The results show that the lowest vibration values were obtained for the grass surface in the direction of all axes, whereas the highest values were obtained on the asphalt and gravel surfaces in the direction of $\mathrm{x}$ and $\mathrm{y}$ axes, and the $\mathrm{y}$ axis, respectively.

The aim of the research is to establish the level of mechanical vibration that affects the operator's hand-arm system on various agrotechnical surfaces in relation to an increased amount of the tractor's work hours. It is expected that the increase in work hours will result in a heightened level of vibration that affects the hand-arm system of the driver of an agricultural tractor.

\section{MATERIALS AND METHODS}

The research was performed on a Landini Powerfarm 100 tractor through a two-year period. Over the first and second research year (2015 and 2016), the tractor reached 5 800 and 6800 hours of work, respectively. The measurements were conducted on the agricultural fields and access roads of the School of Agriculture and Veterinary Medicine in Osijek to establish the values of vibration influencing the hand-arm system of the operator (in the direction of the $x, y$ and $z$ axes). The tractor moved along gravel, asphalt, and grass surfaces. The measurement of vibration was repeated three times, which produced the mean value of vibration used for further research. Each measurement lasted for 30 minutes.

Vibration level measurement was performed in accordance with the standards $[18,19,20]$, which define the limits of vibration exposure, their effects on the operator's health, and include the guidelines for measurements at the workplace. The measurements were performed with a measuring device $M M F V M 30$. A sensor was mounted on the steering wheel with the coordinates set in the direction [20]: $x$ axis: longitudinally (along the axis of motion forward (positive) / backward (negative); $y$ axis: laterally (at the right angle to the motion direction); and $z$ axis: vertically, upward (positive) / downward, vertically to the surface (negative). The weather conditions in 2015 were as follows: air temperature ranged between $29^{\circ} \mathrm{C}$ and $31^{\circ} \mathrm{C}$; relative humidity ranged from $62 \%$ to $64 \%$; the impact of wind was minimal. The weather conditions in 2016 were similar.

The directives [21] and OG [22] contain both the limit values and critical values for the exposure of the hand and arm and they are as follows:

- The limit value for daily exposure based on the reference time of eight hours is $5 \mathrm{~m} \cdot \mathrm{s}^{-2}$;

- The critical value for daily exposure based on the reference time of eight hours is $2.5 \mathrm{~m} \cdot \mathrm{s}^{-2}$.

\section{$3 \quad$ RESULTS AND DISCUSSION}

Compared to the results obtained in 2015, the results for 2016 show a slight vibration deviation in the direction of all three axes measured on all three types of surfaces (gravel, asphalt, and grass surface) (Tab. 1).

\begin{tabular}{|c|c|c|c|c|c|c|}
\hline \multirow{3}{*}{ Surfaces } & \multicolumn{2}{|c|}{$x$ axis } & \multicolumn{2}{|c|}{$y$ axis } & \multicolumn{2}{|c|}{$z$ axis } \\
\hline & \multicolumn{6}{|c|}{ Year } \\
\hline & 2015 & 2016 & 2015 & 2016 & 2015 & 2016 \\
\hline Asphalt & 0.079 & 0.081 & 0.071 & 0.073 & 0.069 & 0.071 \\
\hline Gravel & 0.060 & 0.063 & 0.071 & 0.074 & 0.037 & 0.070 \\
\hline Grass & 0.020 & 0.023 & 0.069 & 0.073 & 0.040 & 0.044 \\
\hline
\end{tabular}

The highest mean vibration values were measured in the direction of $x$ and $z$ axes on the asphalt surface in 2015 and 2016. The highest mean vibration values in 2015 were obtained in the direction of the $y$ axis on the asphalt and gravel road, while the highest mean values were measured on the gravel road in 2016. The lowest vibration values in the direction of the $\mathrm{x}$ axis were measured as follows: in 2015 and 2016 when the tractor moved along a grass surface; in 2015 in the direction of the $y$ axis along a grass surface; in 2016 on the asphalt and grass surface in the direction of the $\mathrm{z}$ axis; in 2015 on the gravel road; in 2016 on the grass surface.

Comparable results were obtained by the authors [23], who measured the vibrations produced by framesaws and bandsaws. The authors established that the obtained vibration level does not carry any health risk to the operator positioned on the framesaw stand even after an eight-hour exposure period. However, a one-hour exposure results in decreased working conditions, which can afflict workers' wellbeing and their efficiency. Deboli et al. [24] measured the vibrations on four tractors equipped with several types of tyres on three different surfaces, i.e. gravel road, asphalt, and a combination between asphalt and gravel road. In the last case, two tyres drove along the gravel road, and the other two along the asphalt road. Irrespective of the tyre type, the lowest vibration was obtained when the tractor moved along the asphalt surface. The vibration level in this case did not reach the allowed limit values, which is in accordance with the results of our research. The results of the descriptive statistics related to the mean values of the obtained vibration in the direction of the $x$ and $z$ axes on the asphalt surface (Tab. 2) show that the standard error was higher in the second year of measurement (2) compared to the first year (1), whereas it remained the same in the direction of the y axis for both years. Furthermore, the variance analysis of the mean values for the obtained vibration impacting the hand-arm system of the driver in the direction of all three axes $(x, y$ and $z$ ) on the asphalt surface shows no statistically significant difference between the measurements in both the first and second year.

Tab. 3 shows the descriptive statistics related to the mean values of the obtained vibration in the direction of $x$ and $y$ axes on the gravel surface. It is discernible that a higher standard error occurs in the second (2) year of measurement compared with the first year (1). Variance analysis of the mean values of vibration in the direction of the $x, y$ and $z$ axes on the gravel surface shows no statistically significant 
difference concerning the mean value of the obtained vibration in both the first and second measurement year.

The highest standard error related to the obtained vibration was measured in the direction of the $x$ and $z$ axes on the grass surface in the second (2) measurement year (Tab. 4). A higher standard error in the direction of the y axis was determined in the first (1) measurement year. The variance analysis of the mean values of vibration in the direction of the $x, y$ and $z$ axes on grass impacting the hand-arm system did not reveal any statistically significant differences between the first (1) and second (2) measurement year.

Table 2 Descriptive statistics and variance analysis for occurred vibrations on asphalt surface

\begin{tabular}{|c|c|c|c|c|c|c|c|}
\hline & $N$ & $\bar{x}$ & $\sigma$ & C.V. $(\%)$ & st. error & $F$ & Sig. $(95 \%)$ \\
\hline \multicolumn{8}{|c|}{$x$ axis } \\
\hline 2015 & 3 & 0.07967 & 0.004509 & 5.65 & 0.002603 & \multirow{3}{*}{0.129} & \multirow{3}{*}{0.738} \\
\hline 2016 & 3 & 0.08100 & 0.004583 & 5.65 & 0.002646 & & \\
\hline Total & 6 & 0.08033 & 0.004131 & 5.14 & 0.001687 & & \\
\hline \multicolumn{8}{|c|}{$y$ axis } \\
\hline 2015 & 3 & 0.07133 & 0.006110 & 8.56 & 0.003528 & \multirow{3}{*}{0.161} & \multirow{3}{*}{0.709} \\
\hline 2016 & 3 & 0.07333 & 0.006110 & 8.33 & 0.003528 & & \\
\hline Total & 6 & 0.07233 & 0.005574 & 7.70 & 0.002275 & & \\
\hline \multicolumn{8}{|c|}{$z$ axis } \\
\hline 2015 & 3 & 0.06900 & 0.005568 & 8.06 & 0.003215 & \multirow{3}{*}{0.243} & \multirow{3}{*}{0.648} \\
\hline 2016 & 3 & 0.07133 & 0.006028 & 8.45 & 0.003480 & & \\
\hline Total & 6 & 0.07017 & 0.005345 & 7.61 & 0.002182 & & \\
\hline
\end{tabular}

Table 3 Descriptive statistics and variance analysis for occurred vibrations on gravel surface

\begin{tabular}{|c|c|c|c|c|c|c|c|}
\hline & $N$ & $\bar{x}$ & $\sigma$ & C.V. $(\%)$ & st. error & $F$ & Sig. $(95 \%)$ \\
\hline \multicolumn{8}{|c|}{$\mathrm{x}$ axis } \\
\hline 2015 & 3 & 0.06033 & 0.002517 & 4.17 & 0.001453 & \multirow{3}{*}{1.391} & \multirow{3}{*}{0.304} \\
\hline 2016 & 3 & 0.06300 & 0.003000 & 4.76 & 0.001732 & & \\
\hline Total & 6 & 0.06167 & 0.002875 & 4.66 & 0.001174 & & \\
\hline \multicolumn{8}{|c|}{$\mathrm{y}$ axis } \\
\hline 2015 & 3 & 0.07100 & 0.004583 & 6.45 & 0.002646 & \multirow{3}{*}{0.519} & \multirow{3}{*}{0.511} \\
\hline 2016 & 3 & 0.07400 & 0.005568 & 7.52 & 0.003215 & & \\
\hline Total & 6 & 0.07250 & 0.004848 & 6.68 & 0.001979 & & \\
\hline \multicolumn{8}{|c|}{$\mathrm{z}$ axis } \\
\hline 2015 & 3 & 0.03667 & 0.032146 & 87.66 & 0.018559 & \multirow{3}{*}{2.326} & \multirow{3}{*}{0.202} \\
\hline 2016 & 3 & 0.07000 & 0.020000 & 28.57 & 0.011547 & & \\
\hline Total & 6 & 0.05333 & 0.030111 & 56.46 & 0.012293 & & \\
\hline
\end{tabular}

Table 4 Descriptive statistics and variance analysis for occurred vibrations on grass surface

\begin{tabular}{|c|c|c|c|c|c|c|c|}
\hline & $N$ & $\bar{x}$ & $\sigma$ & C.V. $(\%)$ & st. error & $F$ & Sig. $(95 \%)$ \\
\hline \multicolumn{8}{|c|}{$x$ axis } \\
\hline 2015 & 3 & 0.02067 & 0.003055 & 14.77 & 0.001764 & \multirow{3}{*}{0.985} & \multirow{3}{*}{0.377} \\
\hline 2016 & 3 & 0.02333 & 0.003512 & 15.05 & 0.002028 & & \\
\hline Total & 6 & 0.02200 & 0.003286 & 14.93 & 0.001342 & & \\
\hline \multicolumn{8}{|c|}{$y$ axis } \\
\hline 2015 & 3 & 0.06900 & 0.006557 & 9.50 & 0.003786 & \multirow{3}{*}{0.768} & \multirow{3}{*}{0.430} \\
\hline 2016 & 3 & 0.07333 & 0.005508 & 7.51 & 0.003180 & & \\
\hline Total & 6 & 0.07117 & 0.005913 & 8.30 & 0.002414 & & \\
\hline \multicolumn{8}{|c|}{$z$ axis } \\
\hline 2015 & 3 & 0.04000 & 0.002000 & 5 & 0.001155 & \multirow{3}{*}{1.920} & \multirow{3}{*}{0.238} \\
\hline 2016 & 3 & 0.04400 & 0.004583 & 10.41 & 0.002646 & & \\
\hline Total & 6 & 0.04200 & 0.003847 & 9.15 & 0.001571 & & \\
\hline
\end{tabular}

\section{CONCLUSION}

The following conclusions can be drawn based on our two-year research:

- The level of vibration that impacts the hand-arm system for all agrotechnical surfaces in the direction of the $x, y$ and $z$ axes was higher in the second (2) measurement year compared to the first (1) measurement year, which is in accordance with the specified hypothesis;

- The highest levels of vibration were obtained for the asphalt surface in the direction of the $x$ and $z$ axes (in 2015 and 2016), as well as in the direction of the $y$ axis for the asphalt and gravel surfaces in 2015, and for the gravel surface in 2016 ;

- The lowest vibration levels were obtained as follows: for the grass surface in the direction of the $x$ axis in 2015 and 2016 ; in the direction of the $y$ axis in 2015; in the direction of the $\mathrm{z}$ axis in 2016. The lowest level for the asphalt surface was obtained in the direction of the $y$ axis in 2016 (the same result was obtained for the grass surface). The lowest level for the gravel surface was obtained in the direction of the $z$ axis in 2015 .

- The research shows that different agrotechnical surfaces (i.e. asphalt, gravel and grass surfaces) produce vibration of various intensity levels that are transmitted to the hand-arm 
system of the agricultural tractor operator. Irrespective of the higher vibration values obtained in the second measurement year, they did not exceed the allowed vibration limit values $\left(5 \mathrm{~m} \mathrm{~s}^{-2}\right)$ affecting the hand-arm system. Therefore, it is assumed that they will not harm the operator's health over an eight-hour work period.

\section{REFERENCES}

[1] Brkić, D., Vujčić, M., Šumanovac, L., Lukač, P., Kiš, D., Jurić, T., \& Knežević, D. (2005). Exploitation of agricultural machinery. Faculty of Agrobiotechnical Sciences Osijek.

[2] Goglia, V., Gospodarić, Z., Košutić, S., \& Filipović, D. (2003). Hand-transmitted vibration from the steering wheel to drivers of small four-wheel drive tractor. Applied Ergonomics, 34(1), 45-49. https://doi.org/10.1016/S0003-6870(02)00076-5

[3] Servadio, P., Marsili, A., \& Belfiore, N. P. (2007). Analysis of driving seat vibrations in high forward speed tractors. Biosystems engineering, 97(2), 171-180. https://doi.org/10.1016/j.biosystemseng.2007.03.004

[4] Stegić, M. (2009). Vibration Theory of the Linear Discrete Mechanical Systems. University textbook, Faculty of mechanical engineering and naval architecture, Zagreb.

[5] Poplašen, D. \& Kerner, I. (2013). Vibrations transmitted to the hands and arms. Safety, 55(4), 389-391. Retrieved from https://hrcak.srce.hr/112849

[6] Goglia, V., Suchomel, J., Žgela, J., \& Đukić, I. (2012). Forestry workers' exposure to vibration in the context of directive 2002/44/EC. Journal of the Forestry Society of Croatia, 5-6, 283-289. Retrieved from

https://hrcak.srce.hr/index.php?show=clanak\&id clanak jezi $\mathrm{k}=126217$

[7] Cardinale, M. \& Wakeling, J. (2005). Whole body vibration exercise: are vibrations good for you. British Journal of Sports Medicine, 39(9), 585-589. https://doi.org/10.1136/bjsm.2005.016857

[8] Goglia, V. \& Beljo-Lučić, R. (1998). Some problems of measuring and evaluation whole body and hand-arm transmitted vibrations. Proceedings of the $26^{\text {th }}$ International Symposium on Agricultural Engineering, Actual Tasks on Agricultural Engineering, Opatija, 61-68.

[9] Goglia, V., Žgela, J., Suchomel, J., \& Đukić, I. (2011). Exposure to hang-arm Transmitted vibration at forest nursery and thinning. Human Resources Management and Ergonomics, $5(1), 45-55$. Retrieved from https://frcatel.fri.uniza.sk/hrme/archi.html

[10] Suchomel, J. \& Slancik, N. (2005). Influence of some ergonomic criterions on modeling and optimization technology in forestry. Proceedings of the International Conference Management of human potential in enterprises, Žilina, 354359.

[11] Fahy, F. \& Thompson, D. (2015). Fundamentals of Sound and Vibration, Second Edition. University textbook, Institute of Sound and Vibration Research, University of Southampton, Southampton. Retrieved from https://books.google.hr/ books?hl=hr\&lr=\&id=znd3CAAAQBAJ\&oi=fnd\&pg=PP1\& $\mathrm{dq}=11 . \% 09$ Fahy,$+\mathrm{F} .,+$ Thompson,+ D. + Fundamentals + of + Sou nd + and + Vibration, + Second + Edition. + Institute + of + Sound + an $\mathrm{d}+$ Vibration + Research, + University + of + Southampton,,+ South ampton, +2015 .\&ots $=$ BP1zI0Wbpa\&sig=HSHPF7daxNGN6G M-XRd_gKP3U6I\&redir_esc $=\mathrm{y} \# \mathrm{v}=$ onepage \&q\& $\mathrm{f}=$ false

[12] Bogadi-Šre, A. (1993). Whole body vibration syndrome - a medical problem requiring more attention. Archives of Industrial Hygiene and Toxicology, 44(3), 269-279. Retrieved from https://hrcak.srce.hr/index.php?show=clanak\&id_clanak jezik $=216606$

[13] Zeng, X. (2016). Modeling predictors of whole body vibration exposure among Saskatchewan farmers: A key step in low back disorder prevention. University of Saskatchewan, Saskatoon. Retrieved from https://harvest.usask.ca/handle/10388/7389

[14] Pobedin, A. V., Dolotov, A. A., \& Shekhovtsov, V. V. (2016). Decrease of the vibration load level on the tractor operator working place by means of using of vibrations dynamic dampers in the cabin suspension. Proceedia Engineering, 150, 1252-1257. https://doi.org/10.1016/j.proeng.2016.07.136

[15] Gomez-Gil, J., Gomez-Gil, F. J., \& Martin-de-Leon, R. (2014). The influence of tractor-seat height above the ground on lateral vibrations. Sensors, 14(10), 19713-19730. https://doi.org/10.3390/s141019713

[16] Barač, Ž., Vidaković, I., Zimmer, D., \& Ermenić, V. (2017). The relationship of agrotechnical interventions on the level of vibrations produced and their influence on the system handarm of the operator of the tractor. Proceedings of the 52th Croatian and $12^{\text {th }}$ international symposium on agriculture, Dubrovnik, 628-631. Retrieved from https://www.cabdirect.org/cabdirect/abstract/20173178505

[17] Barač, Ž., Plaščak, I., Jurišić, M., Zimmer, D., Vidaković, I., \& Laslo, J. (2017). The influence of different agricultural surfaces on produced vibration that affect the system hand-arm of operator. Proceedings \& abstract of the $10^{\text {th }}$ International Scientific/Professional Conference Agriculture in Nature and Environment Protection, Vukovar, 187-190. Retrieved from https://www.cabdirect.org/cabdirect/abstract/20173257533

[18] HZN (1999). Mechanical vibration and shock - Evaluation of human exposure to whole-body vibration - Part 1: General requirements, HRN ISO 2631-1. Croatian Standards Institute, Zagreb, 1999.

[19] HZN (2008). Mechanical vibration - Measurement and evaluation of human exposure to hand-transmitted vibration Part 1: General requirements, HRN ISO 5349-1, Croatian Standards Institute, Zagreb.

[20] HZN (2008). Mechanical vibration - Measurement and evaluation of human exposure to hand-transmitted vibration Part 2: Practical guidance for measurement at the workplace, HRN ISO 5349-2, Croatian Standards Institute, Zagreb, 2008.

[21] EC (2002). Council Directive on the minimum health safety requirements regarding the exposure of workers to the risks arising from physical agents (vibration), J Eur Commun, EEC 89/391, 2002/44. Retrieved from https://eur-lex.europa.eu/legalcontent/HR/TXT/?uri=CELEX:02002L0044-20081211

[22] OG 155/2008. Rule book on protection from the risk of exposure to vibration at work. Ministry of economy, entrepreneurship and crafts, Republic of Croatia, Zagreb.

[23] Đukić, I. \& Goglia, V. (2007). Noise and vibration in using framesaws and bandsaws. Scientific journal of wood technology, 58(1), 19-22. Retrieved from

https://hrcak.srce.hr/index.php?show=clanak\&id_clanak_jezi $\mathrm{k}=19667$

[24] Deboli, R., Calvo, A., Preti, C., Palietto, G. (2008). Whole body vibration (wbv) transmitted to the operator by tractors equipped with radial tires. International conference Innovation Technology to Empower Safety, Health and Welfare in Agriculture and Agro-food Systems, Ragusa, 1-10. Retrieved from http://www.ragusashwa.it/CD 2008/lavori/ TOPIC7/poster/DEBOLI-1.pdf 
Authors' contacts:

Željko BARAČ, MSc, Research Assistant Corresponding author

Faculty of Agrobiotechnical Sciences Osijek, Vladimira Preloga 1, 31000 Osijek, Croatia zbarac@fazos.hr

Ivan PLAŠČAK, PhD, Associate Professor Faculty of Agrobiotechnical Sciences Osijek, Vladimira Preloga 1, 31000 Osijek, Croatia iplascak@fazos.hr

Tomislav JURIĆ, PhD, Full Professor Faculty of Agrobiotechnical Sciences Osijek, Vladimira Preloga 1, 31000 Osijek, Croatia tjuric@fazos.hr

Pavo BALIČEVIĆ, PhD, Full Professor Faculty of Agrobiotechnical Sciences Osijek, Vladimira Preloga 1, 31000 Osijek, Croatia pbalicevic@fazos.hr

Vinko DUVNJAK, PhD, Scientific Adviser Agricultural Institute Osijek,

Južno predgrađe 17, 31000 Osijek, Croatia

vinko.duvnjak@poljinos.hr

Mladen JURIŠIĆ, PhD, Full Professor Faculty of Agrobiotechnical Sciences Osijek, Vladimira Preloga 1, 31000 Osijek, Croatia mjurisic@pfos.hr

Goran HEFFER, PhD, Full Professor Faculty of Agrobiotechnical Sciences Osijek, Vladimira Preloga 1, 31000 Osijek, Croatia hgoran@fazos.hr

Monika MARKOVIĆ, PhD, Assistant Professor Faculty of Agrobiotechnical Sciences Osijek, Vladimira Preloga 1, 31000 Osijek, Croatia mmarkovic@fazos.hr 